\title{
Evolution of Microstructures and Interfaces in Compositionally Graded Mixed Oxide Thin Films for Nanoelectronics and Energy
}

\author{
Avnish Singh Pal ${ }^{1}$, Ankit Singh ${ }^{1}, \mathrm{RK}$ Mandal $^{1}$ and Joysurya Basu ${ }^{{ }^{*}}$ \\ ${ }^{1 .}$ Department of Metallurgical Engineering, Indian Institute of Technology (BHU), Varanasi, Varanasi, \\ UP, India. \\ * Corresponding author: jbasu.met@iitbhu.ac.in
}

Continuously diminishing fossil fuel resources, environmental concerns, changing geopolitical scenario have incentivized the search for new energy materials and technologies [1]. In order to meet the challenges, it is important to discover materials and invent technologies with higher capacity, longer lifetime coupled with environmental friendliness. Several metal oxides have been discovered which partially and completely meet these challenges [2]. Several strategies such as protective coating, coreshell nanostructuring and compositional gradation have been implemented in order to improve their life time and properties [3]. In order to correlate the properties with the underlying structure at the atomic scale, it is important to study their microstructure and interfaces in detail. In the present work electron microscopy investigation of compositionally graded cathodes and mixed-oxide chess board nanostructures [4] has been carried out in order to understand their functional properties.

In the present work, compositionally graded cathode of lithium nickel oxide and lithium manganese oxide has been deposited onto single-crystal $\mathrm{Nb}$-doped $\mathrm{SrTiO}_{3}$ substrate by pulse laser deposition. The composition gradation was obtained by depositing at $873 \mathrm{~K}$ and by varying the deposition time of each individual oxide. In addition to that chess board nanostructures of $\mathrm{Nd}_{2 / 3-\mathrm{x}} \mathrm{Li}_{3 \mathrm{x}} \mathrm{TiO}_{3}(0.06<\mathrm{x}<0.16)$ and $\mathrm{Co}_{0.6} \mathrm{Fe}_{\mathrm{x}} \mathrm{Mn}_{2.4-\mathrm{x}} \mathrm{O}_{4}(0.6<\mathrm{x}<1.0)$ has been developed starting from the mix of individual metal oxide powder in appropriate proportion by thermal annealing treatment. Electron transparent samples were made by conventional techniques. The phases, microstructures and the interface have been characterized by TEM. The interface between $\mathrm{SrTiO}_{3}$ and the oxide thin film is structurally sharp and no reaction product is observed at the interface. No defect is observed at the thin film/substrate interface. The oxide thin film is apparently single crystalline as no grain boundary is observed in the film. The presence of $\mathrm{Li}^{+}$ions in the film can be confirmed by the characteristic energy-loss edge in the EELS spectrum. Although there is no grain boundary present in the film, in STEM-HAADF image a definite contrast is observed over couple of nanometers, which indicates composition gradation in the sample, which was deposited at 873K. EDS composition mapping from the film and the interface indicates that the film is Ni-rich near the $\mathrm{SrTiO}_{3}$ interface and away from the interface the distribution of $\mathrm{Ni}$ and $\mathrm{Mn}$ ions is almost homogeneous. Diffraction pattern from the film and the substrate indicates that there is an epitaxial relationship with the $\mathrm{SrTiO}_{3}$ substrate. However, the diffraction pattern from the film cannot be indexed unambiguously as diffraction characteristics from rhombohedrally distorted $\mathrm{LiNiO}_{2}$ and cubic $\mathrm{LiMn}_{2} \mathrm{O}_{4}$ are almost identical. By extensive phase contrast imaging and image simulation it has been determined that ordered and disordered rhombohedral $\mathrm{LiNiO}_{2}$ and cubic $\mathrm{LiMn}_{2} \mathrm{O}_{4}$ spinel are present in the film. Due to the epitaxial relationship and absolute coherence between the phases, grain boundaries are not observed under normal imaging conditions (figure 1). The epitaxial relationships are [112] of $\mathrm{SrTiO}_{3}$ is parallel to [112] of $\mathrm{LiMn}_{2} \mathrm{O}_{4}$ and [1-10] of $\mathrm{LiNiO}_{2}$ and (111) of $\mathrm{SrTiO}_{3}$ is parallel to (111) of $\mathrm{LiMn}_{2} \mathrm{O}_{4}$ and (006) of $\mathrm{LiNiO}_{2}$. $\mathrm{Nd}_{2 / 3-\mathrm{x}} \mathrm{Li}_{3 \mathrm{x}} \mathrm{TiO}_{3}$ and $\mathrm{Co}_{0.6} \mathrm{Fe}_{\mathrm{x}} \mathrm{Mn}_{2.4-\mathrm{x}} \mathrm{O}_{4}$ after thermal treatment shows alternate bright and dark nanodomains. Compositional analysis of the domains indicates that in $\mathrm{Nd}_{2 / 3-\mathrm{x}} \mathrm{Li}_{3 \times} \mathrm{TiO}_{3}$ the domains are alternately Li-rich or Li-lean and in $\mathrm{Co}_{0.6} \mathrm{Fe}_{\mathrm{x}} \mathrm{Mn}_{2.4-\mathrm{x}} \mathrm{O}_{4}$ the domains are alternately Mn-rich and Mn-lean. 
Each of the domains have been characterized by nano beam electron diffraction and it has been found that the domains are tetragonal and cubic in structure (figure 2). Complicated twin related growth is observed at the interface [5].

In the compositionally graded film, even though the film quality is excellent, due to the disordering of $\mathrm{LiNiO}_{2}$, its electrochemical properties are poisoned. Furthermore, due to this epitaxial relationship, cation layers in the $\mathrm{LiNiO}_{2}$ phase are not perpendicular on the substrate. This will introduce further kinetic hindrance to the $\mathrm{Li}^{+}$migration during biasing. In the spinel phase, $\mathrm{Li}^{+}$ions being tetrahedrally coordinated, it has to follow random diffusion path during biasing. These factors will kinetically deteriorate the electrochemical activity of the cathode. In the presentation, structural and compositional details at atomic scale will be presented in order to explain the atomistic origin of electrochemical activity in such materials.

\section{References:}

[1] Z Chen et al., MRS Bull. 36 (2011), p. 498.

[2] Y Cho et al., J. Cho, Adv. Energy Mater. 1 (2011), p. 821.

[3] W Zhou et al., Sci. Reports 1 (2011), p. 155.

[4] BS Guiton and PK Davies, Nature Mater. 6 (2007), p. 586.

[5] Y Ni and AG Khachaturyan, Nature Mater. 8 (2009), p. 410.

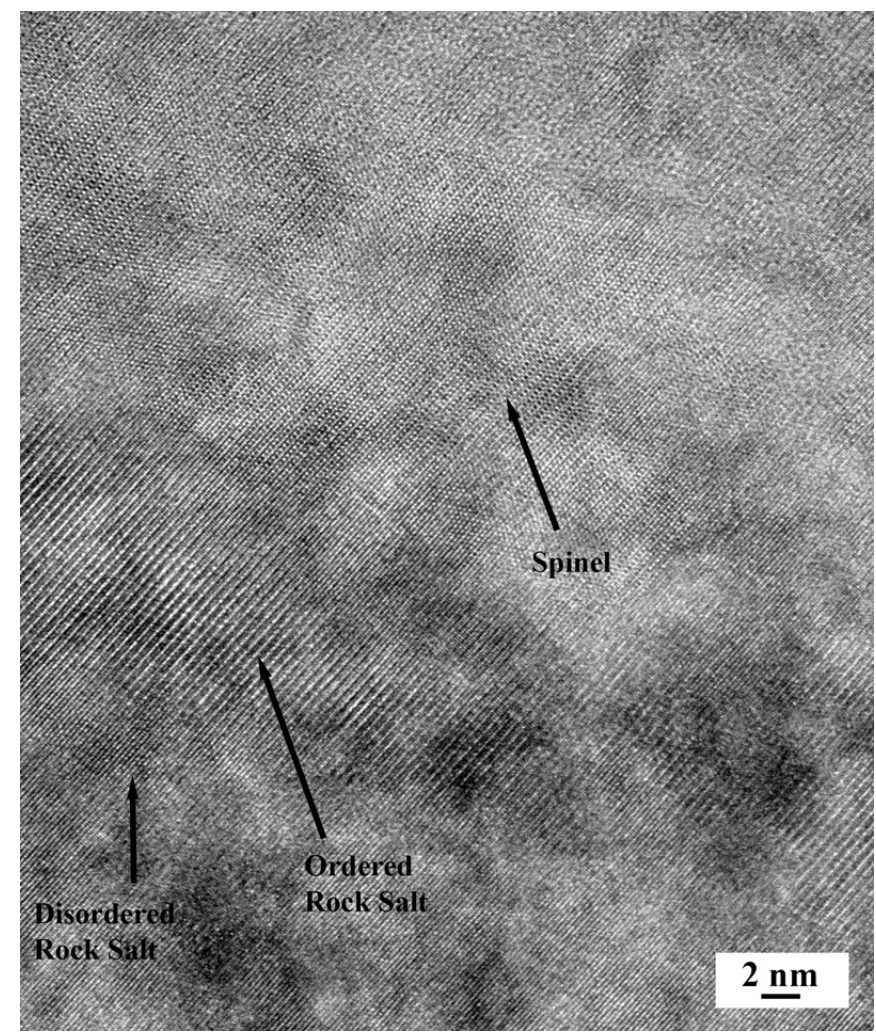

Figure 1. High resolution phase contrast image of compositionally graded cathode. Perfectly coherent interface between spinel, ordered and disordered rock salt is observed.
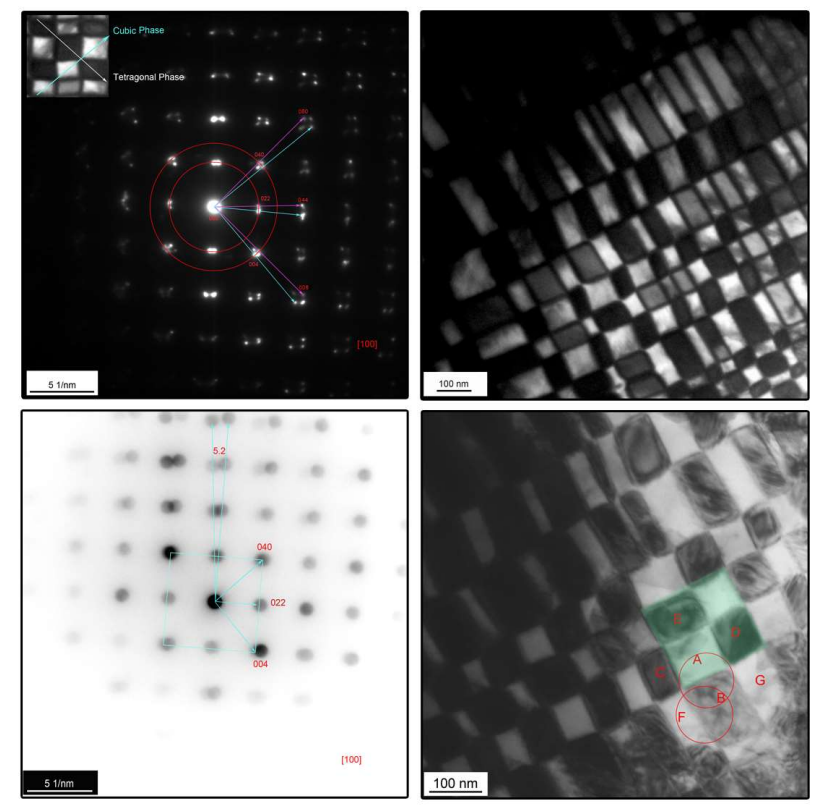

Figure 2. Bright field image and diffraction pattern of chess board microstructure of $\mathrm{Co}_{0.6} \mathrm{Fe}_{\mathrm{x}} \mathrm{Mn}_{2.4-\mathrm{x}} \mathrm{O}_{4}$ mixed oxide 